\title{
Electrochemical measurement of the size of microband electrodes: A theoretical study
}

Danlei Li, Chuhong Lina , Christopher Batchelor-McAuley, Lifu Chen, Richard G. Compton*

Department of Chemistry, Physical and Theoretical Chemistry Laboratory, University of Oxford, South Parks Road, Oxford OX1 3QZ, United Kingdom

*Corresponding author:

Email: Richard Compton Richard.compton@chem.ox.ac.uk

Phone: +44(0) 1865275957

Fax: +44(0) 1865275410

${ }^{a}$ Current address: Key Laboratory of Environmental Optics and Technology, Institute of Intelligent Machines, Chinese Academy of Sciences, Hefei 230031, PR China.

\section{Abstract}

A theoretical proof-of-concept study demonstrating the use of an electrochemical method to measure the width and length of a band electrode of unknown dimensions is presented. It is found that by using a fully irreversible redox couple it is possible to characterise a band electrode without prior knowledge of the electron transfer rate constant or the formal potential. By using the peak-topeak separation $\left(E_{p-p}\right)$ and the magnitude of the ratio of backward peak current to forward peak current $\left(||_{\text {backward }} / I_{\text {forward }} \mid\right)$ as diagnostic parameters that characterise the shape and size of the resulting voltammetric wave, the band width can be estimated with an error of less than $4 \%$ compared to its true value and with an error in length of less than $1 \%$. 


\section{Introduction}

Macroelectrodes have been widely used for investigating the electrochemical mechanisms of heterogeneous processes and the catalytic activities of various metal surfaces towards, for example, the hydrogen evolution and hydrogen oxidation reactions[1,2]. However, the large capacitance and low cell time constant associated with their macroscopic $(\mathrm{mm})$ size and the requirement of using a conducting electrolyte, limits their value in the mechanistic study of fast interfacial processes and also, in electroanalysis[3]. Microelectrodes have opened new possibilities for measurements which are difficult or impossible to achieve using macroelectrodes[4-8]. The decrease in size of the electrode to the micron scale alters the voltammetric behaviour offering advantageous properties[5,9-11]. First, the effect of the solution phase resistance becomes smaller due to the decreased size of the electrode[9,12]. Second, higher current densities are obtained on microelectrodes due to the enhanced mass transport of electroactive species to and from the electrode surface[9,12]. Third, they can be used in samples with small volumes as is required in medical and biological research[13,14]. However, microelectrodes give low absolute currents, typically in the nanoampere scale, hence requiring the use of sensitive current amplifiers. This requirement of using specialised equipment can have significant implications for the cost associated with for example, mass-produced point-of-use analytical devices. One strategy to address this problem without resorting to the use of electrode arrays is using microelectrodes with cylindrical or band geometries[15]. Band-shaped and cylindrical microelectrodes have the characteristics of both macroelectrodes and microelectrodes because they are macroscopic in one dimension and microscopic in the other, offering higher sensitivity with larger total current output. The magnitude of the current varies directly with the electrode length. In this work, we focus on the single microband geometry, noting that although the current at a microband electrode is often approximated to that of a hemicylinder of equivalent area $(r=w / \pi$, where $r$ is the radius of the hemicylinder and $w$ is the width of the band), there is no true equivalence between these two geometries[4]. In the following, we study the true, not the approximate geometry.

Fabrication methods for band electrodes have been widely discussed in the literature and include thin film deposition techniques and a lamination method[16-19]. Girault et al. presented a method for the construction of band electrode based on thin film laminated materials[16], whilst the Compton group has successfully used thermal lamination method of metal foils, wires or meshes to fabricate microbands, microdiscs and a linear array of microdisc electrodes[18]. Band electrodes with a submicrometer width can be characterised using Optical Microscopy or Scanning Electron Microscopy (SEM) $[12,17,20]$. However, the successful use of SEM requires a clear contrast between the materials of the band and the external insulating layers. Microdisc electrodes are routinely sized and characterised voltammetrically where the magnitude of a steady-state diffusional current is used to calibrate the efficient electrode radius. For a microband electrode, rather than a single radius, there are two unknowns - the length and the width. An electrochemical method is described in this work to provide a general and easy approach for general use to calibrate the size of the unknown electrode.

Accurate electrode sizing measurements using a voltammetric method requires the appropriate choice of the electroactive redox couple to be used. Since a redox couple involving the transfer of multiple electrons would offer mechanistic complexity, fully reversible or irreversible redox couples which undergo single electron transfer are preferred. In particular well characterised standard redox 
couples such as $\mathrm{Ru}\left(\mathrm{NH}_{3}\right)_{6}^{2+/ 3+}$ and $\mathrm{Fe}(\mathrm{CN})_{6}^{3-/ 4-}$ are often used to calibrate the size of both macroelectrodes and microelectrodes due to their well-known diffusion coefficients[15,21]. The voltammetric behaviour of a band electrode has been studied using such standard redox couples[12,21,22]; however, the electrochemical characterisation of the electrode dimensions has not been attempted. In this paper, we use a home-written simulation method developed specifically for a single microband electrode with the expectation that the dimensions of a band electrode can be characterised by comparing experimental and simulated voltammograms by analysing the kinetic information obtained from independent experiments. Note that the simulations are rigorous and do not depend on analogies being made between cylinders and bands.

Electrode processes in both the reversible and irreversible limits are considered. On the one hand, for a fully reversible one electron transfer process, knowledge of the electrode kinetics (standard rate constant and transfer coefficient) is not needed. The formal potential $\left(E_{f}\right)$ can be estimated as the mid-point potential of forward and backward peak potentials $\left(E_{p(f o r w a r d)}\right.$ and $\left.E_{p(b a c k w a r d)}\right)$ : in a conventional linear diffusional cyclic voltammogram. Conversely, using a fully irreversible redox couple requires that the kinetic parameters are known. However, the transfer coefficient can be easily calculated from Tafel analysis using a Tafel region corresponding to $1 \%$ to $10 \%$ of the peak current[23]. In both cases, the value of diffusion coefficient of the electroactive species can be found in the literature or measured using a microdisc electrode from steady-state voltammetry[12,21,22]. In this paper, we first develop a theoretical study showing the viability of the method and establish the requirements of the optimal redox couple for microband sizing to facilitate subsequent experiments. Thus, this theoretical study validates how simple voltammetric measurements can be used to characterise the length and width of a band electrode.

\section{Theory and simulation}

\subsection{Butler-Volmer (BV) theory}

Here we consider a heterogeneous one electron transfer oxidative process (Eq.1) on a microband electrode in both the fully reversible and irreversible limits:
$\mathrm{A} \rightleftarrows \mathrm{B}+e^{-}$
Eq. 1

where the reactant and product are assumed to have unequal diffusion coefficients with only reactant present in the bulk solution.

Assuming that the electron transfer kinetics are described by the Butler-Volmer (BV) equation, the oxidative and reductive rate constants $\left(k_{a}, k_{c}\right)$ are functions of the standard rate constant $\left(k^{0} /\right.$ $\left.m s^{-1}\right)$, the formal potential of redox couple $\mathrm{A} / \mathrm{B}\left(E_{f} / V\right)$ and anodic and cathodic transfer coefficients $\left(\alpha_{a}, \alpha_{c}\right)$ :

$$
\begin{array}{ll}
k_{a}=k^{0} \exp \left[\alpha_{a} \theta\right] & E q .2 \\
k_{c}=k^{0} \exp \left[-\alpha_{c} \theta\right] & E q .3
\end{array}
$$

where the anodic transfer coefficient $\alpha_{a}$ and the cathodic transfer coefficient $\alpha_{c}$ are between 0 and $1, \alpha_{a}+\alpha_{c}=1$, and $\theta$ is the dimensionless potential given by: 
$\theta=\frac{F}{R T}\left(E-E_{f}\right)$

Eq. 4

where $E(V)$ is the potential of the working electrode, $F$ is the Faraday constant $\left(96,485 \mathrm{C} \mathrm{mol}^{-1}\right), R$ is the gas constant $\left(8.314 \mathrm{~J} \mathrm{~mol}^{-1} \mathrm{~K}^{-1}\right)$ and $\mathrm{T}$ is the temperature in $\mathrm{K}$.

Under BV theory, for a one electron transfer oxidative process, the electrochemical flux can be described as below:

$j=-k_{a}[A]_{0}+k_{c}[B]_{0}=-k^{0}[A]_{0} e^{\alpha_{a} \theta}+k^{0}[B]_{0} e^{-\alpha_{c} \theta} \quad E q .5$

where $j\left(\mathrm{~mol} \mathrm{~m}^{-2} \mathrm{~s}^{-1}\right)$ is the flux of electrons, $[A]_{O}$ and $[B]_{0}\left(\mathrm{~mol} \mathrm{~m}^{-3}\right)$ are the concentrations of reactant $A$ and product $B$ at the electrode surface, separately.

This electrochemical flux for the one-electron transfer reaction can be directly related to the measured current by:

$I=-\int F j d A \quad E q \cdot 6$

where I $(A)$ is the anodic or cathodic current, $A\left(\mathrm{~m}^{2}\right)$ is the electrode area.

\subsection{Numerical simulation procedures}

A bespoke programme for single microband simulation was written so as to avoid approximating the band as a cylinder. The convergence for this programme was tested and the validation is presented in the SI Section 6. Figure 1 (a) gives the geometry of the microband electrode. Since the length of the microband is assumed to be of a macroscale, diffusion in the y dimension can be considered constant and only the coordinates $x$ and $z$ are considered in the simulation. Figure 1 (b) presents the two-dimensional simulation space. The concentration distribution of the reactant as a function of time and space is calculated via solving the diffusion equation coupled with boundary conditions as shown in Figure 1 (b). Dimensionless parameters are applied. The transformations between the dimensional and dimensionless parameters are listed in Table 1. The diffusion coefficients of the redox couples $A$ and $B$ are different and initially there is only the reactant in bulk solution. The boundary condition at the microband electrode is the BV equation and can be written as:

$d_{A} \frac{\partial C}{\partial Z}=K^{0} \exp \left(\alpha_{a} \theta\right) C_{A}-K^{0} \exp \left(-\alpha_{c} \theta\right) C_{B} \quad$ Eq. 7

$d_{B} \frac{\partial C}{\partial Z}=-K^{0} \exp \left(\alpha_{a} \theta\right) C_{A}+K^{0} \exp \left(-\alpha_{c} \theta\right) C_{B} \quad E q .8$

where $\alpha_{a}+\alpha_{c}=1[24,25] . K^{0}$ is the dimensionless form of the standard electrochemical rate constant, $d_{\mathrm{A}}$ and $d_{\mathrm{B}}$ are the dimensionless diffusion coefficients of species $\mathrm{A}$ and $\mathrm{B}, C_{\mathrm{A}}$ and $C_{\mathrm{B}}$ are the dimensionless concentrations of species $A$ and $B$. To simulate the cyclic voltammetry, the applied potential is defined as a function of the time as:

$\theta=\left\{\begin{array}{cl}\theta_{i}+\sigma \tau & \tau \leq \frac{\theta_{r}-\theta_{i}}{\sigma} \\ \theta_{r}-\sigma\left(\tau-\frac{\theta_{r}-\theta_{i}}{\sigma}\right) & \tau>\frac{\theta_{r}-\theta_{i}}{\sigma}\end{array}\right.$ 
$\theta_{i}$ and $\theta_{f}$ are the initial and final applied potentials, respectively. $\left[\theta_{i} \theta_{f}\right]$ is the voltammetric potential window. For the oxidative reaction discussed in this work, $\theta_{i}<\theta_{f}$. The dimensionless current $J$ measured on the microband electrode is calculated from the concentration gradient at the electrode surface:

$J=2 \int_{0}^{1} \frac{\partial C_{A}}{\partial Z} d X$

The theoretical model is numerically solved by the finite difference method and the alternating direction implicit (ADI) method[26]. The simulation program is written in Matlab R2017a and run on an Intel(R) Xeon(R) 3.60G CPU.
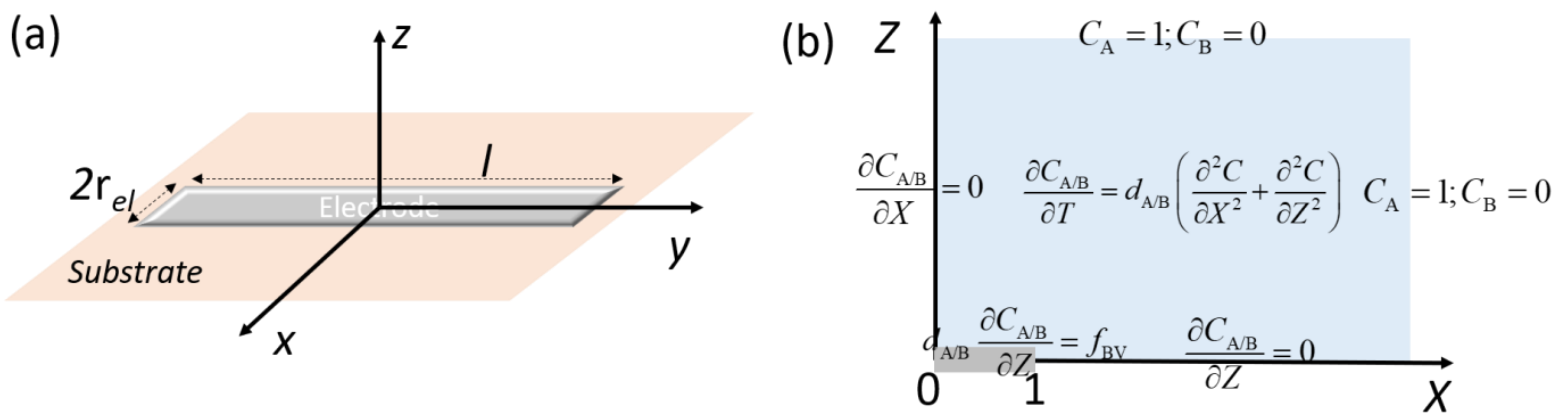

Figure 1 (a) A microband electrode in the Cartesian coordinate. (b) The simulation model for the redox reaction on the microband electrode. $f_{\mathrm{BV}}$ is the Butler-Volmer equation as written in Eq.7 and Eq.8.

Table 1 Interpretation and transformation of dimensionless parameters.

\begin{tabular}{|c|c|c|}
\hline $\begin{array}{l}\text { SI unit } \\
\text { parameters }\end{array}$ & Interpretation & Dimensionless parameters \\
\hline$r_{\mathrm{el}}(\mathrm{m})$ & Half of the electrode width (microband); & $R_{\mathrm{el}}=r_{\mathrm{el}} / r_{\mathrm{el}}=1$ \\
\hline$L_{\mathrm{el}}(\mathrm{m})$ & Length of the microband & \\
\hline$x(m)$ & Space coordinate, parallel to the electrode surface & $X=x / r_{\mathrm{el}}$ \\
\hline$z(\mathrm{~m})$ & $\begin{array}{l}\text { Space coordinate, perpendicular to the electrode } \\
\text { surface }\end{array}$ & $Z=z / r_{\mathrm{el}}$ \\
\hline$c_{\text {bulk }}(\mathrm{mM})$ & Concentration in the bulk solution & $C_{\text {bulk }}=c_{\text {bulk }} / c_{\text {bulk, } \mathrm{A}}$ \\
\hline$c(\mathrm{mM})$ & Concentration & $C=c / c_{\text {bulk,A }}$ \\
\hline$D\left(\mathrm{~m}^{2} \mathrm{~s}^{-1}\right)$ & Diffusion coefficient & $d=D / D_{\mathrm{A}}$ \\
\hline$t(s)$ & Reaction time & $\tau=t^{*} D_{\mathrm{A}} / r_{\mathrm{el}}^{2}$ \\
\hline$F\left(C \mathrm{~mol}^{-1}\right)$ & Faraday constant $\left(96485 \mathrm{C} \mathrm{mol}^{-1}\right)$ & \\
\hline
\end{tabular}




\begin{tabular}{lll}
\hline $\boldsymbol{R}\left(\mathrm{J} \cdot \mathrm{mol}^{-1} \cdot \mathrm{K}^{-1}\right)$ & Gas constant $\left(8.3145 \mathrm{~J} \cdot \mathrm{mol}^{-1} \cdot \mathrm{K}^{-1}\right)$ & \\
$\boldsymbol{T}(\mathrm{K})$ & Experiment temperature $(298.2 \mathrm{~K})$ & \\
$\boldsymbol{E}_{\mathrm{f}}(\mathrm{V})$ & Formal potential & $\theta=\left(E-E_{\mathrm{f}}\right) F /(R T)$ \\
$\boldsymbol{E}(\mathrm{V})$ & Applied electrode potential & $K=k^{0} r_{\mathrm{el}} / D_{\mathrm{A}}$ \\
$\boldsymbol{k}^{0}\left(\mathrm{~m} \mathrm{~s}^{-1}\right)$ & Standard electrochemical rate constant & $\sigma=v F r_{\mathrm{el}}{ }^{2} /\left(R T D_{\mathrm{A}}\right)$ \\
$\boldsymbol{v}\left(\mathbf{V ~ s}^{-1}\right)$ & Scan rate & $J=I /\left(F D_{\mathrm{A}} C_{\mathrm{bulk}, \mathrm{A}} L_{\mathrm{el}}\right)$ \\
$\boldsymbol{I}(\mathbf{A})$ & Current & \\
\hline
\end{tabular}

\section{Results and discussion}

Voltammograms on a microband electrode were simulated for the cases of both fully reversible and fully irreversible processes. We first aim to assess whether it is possible to electrochemically measure the unknown width and length of a band electrode using an electroactive redox couple. Second, we explore how the redox couple can be used to characterise the band electrode with the minimum number of parameters known about the selected redox couple. The results presented in this paper focus exclusively on oxidative voltammetry, but they are also equally applicable to reductive processes.

Unlike spherical or microdisc electrodes, a true steady state is impossible to obtain on band electrodes under diffusion-controlled conditions because the mass transport operates in two dimensions. This situation leads to a quasi-steady state regime[4,12,27]; single microband electrodes exhibit quasi-steady state limiting currents at high overpotentials. The diffusional character becomes more 'linear' for a wider band electrode of a given length (I), resulting in an increasingly peaked waveshape. The magnitude of the current scales linearly with the length of the band. It is the variability of waveshape which gives the possibility of the measurement of width and length of a given band electrode from purely voltammetric measurements, as will be shown below.

Reaction (1) was first simulated as a fully reversible electron transfer process at a microband electrode where species $A$ and $B$ have equal diffusion coefficients. Although the waveshape become more peaked with wider bands, for a reversible process, the changes in the waveshape are relatively subtle. Consequently, as shown in SI Section 1 (Figure 1), the forward and backward peak potentials are too insensitive to the electrode dimensions to be a useful measurement technique. Hence in this work, for characterising the electrode dimensions, a reversible redox couple is not optimal for measuring the width and length of a band electrode. The following section is therefore focused on simulations for fully irreversible processes where the redox couple has either equal or unequal diffusion coefficients.

\subsection{Fully irreversible redox couple with equal diffusion coefficients}

Voltammograms for a fully irreversible redox couple with variable electron transfer rate constant $\left(k^{0}\right)$ 
and transfer coefficient $\left(\alpha_{a}\right.$ and $\alpha_{c}$ ) values on band electrodes with variable widths were simulated using the above described home-written programme. In this subsection, the reactant and product are assumed to have equal diffusion coefficients and only the reactant is taken to be present in the bulk solution. The results shown in the main text present the cases for the anodic and cathodic transfer coefficients both equal to 0.5 . Results for other transfer coefficients are considered in data shown in the SI Section 2 with similar conclusions as are made below.

The simulated voltammograms at a given electron transfer rate constant $\mathrm{k}^{0}$ of $1 \times 10^{-7} \mathrm{~m} \mathrm{~s}^{-1}$ on a band electrode with variable widths are shown in Figure $2(\mathrm{a})$ as an example, with a scan rate of $0.2 \mathrm{~V} \mathrm{~s}^{-1}$ and anodic transfer coefficient $\alpha_{a}$ of 0.5 . The low value of $k^{0}$ ensures fully irreversible electron transfer. The value of diffusion coefficient $D$ was chosen arbitrarily as $1 \times 10^{-9} \mathrm{~m}^{2} \mathrm{~s}^{-1}$. In order to compare the waveshape of electrodes with variable widths directly, the simulated voltammograms were normalised to the peak current (Figure 2(a)), revealing clearly distinguishable waveshapes. As shown in Figure 2, the peak-to-peak separation becomes markedly smaller with increasing band width and the backward current increases for a wider band. From Figure 2(a) it appears that it is possible, at least in principle, to use a fully irreversible redox couple to estimate the width and length of a band electrode. Results for other $k^{0}$ values are presented in the SI Section 4. Inspection of these data confirms the principle for other 'fully irreversible' couples albeit with different transfer coefficients.
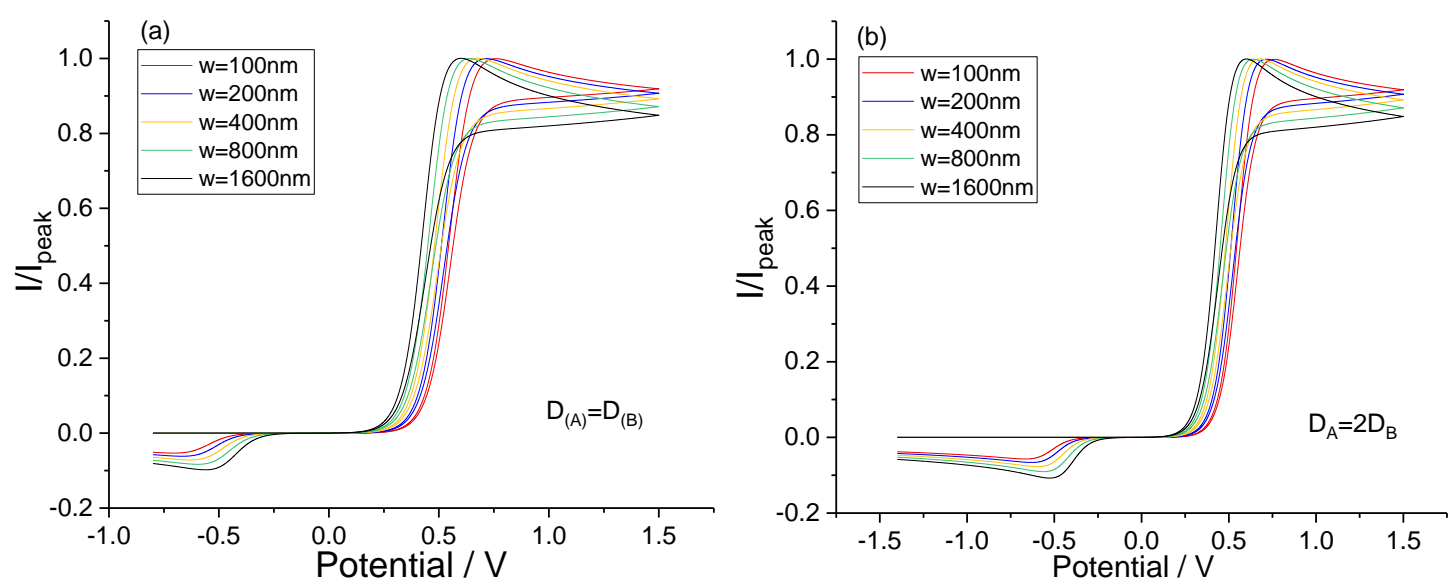

Figure 2 (a) Normalised voltammograms for a band electrode with variable widths for a fully irreversible redox couple with equal diffusion coefficients. The diffusion coefficient $D_{(A)}=D_{(B)}=1 \times 10^{-9} \mathrm{~m}^{2} \mathrm{~s}^{-1}$. (b) Normalised voltammograms for a band electrode with variable widths for a fully irreversible redox couple with unequal diffusion coefficients. The diffusion coefficients of $A$ and $B: D_{(A)}=1 \times 10^{-9} \mathrm{~m}^{2} \mathrm{~s}^{-1}, D_{(B)}=5 \times 10^{-10} \mathrm{~m}^{2} \mathrm{~s}^{-1}$. Parameters in all simulations: $\mathrm{v}=0.2 \mathrm{~V} \mathrm{~s} \mathrm{~s}^{-1}, E_{\mathrm{f}}=0 \mathrm{~V}$, $\mathrm{l}=1 \times 10^{-2} \mathrm{~m}, \mathrm{k}^{0}=1 \times 10^{-7} \mathrm{~m} \mathrm{~s}^{-1}$, transfer coefficient $\alpha_{\mathrm{a}}=\alpha_{\mathrm{c}}=0.5$.

As the length of the electrode only serves to scale the current associated with the electrode, measuring the band width accurately is the major task associated with characterising the electrode geometry.

The values of the forward or backward peak potentials $\left(E_{p(\text { forward })} / E_{p(\text { backward })}\right)$, the peak-to-peak separation $\left(E_{p-p}\right)$ and the ratio of the magnitude of the backward peak current to the forward peak current $\left(\left|\mathrm{I}_{\mathrm{b}} / \mathrm{I}_{\mathrm{f}}\right|\right)$ are easily measured from an experimental voltammogram and can be used to characterise and quantify the waveshape. Consequently, plots describing $E_{p(f o r w a r d)}$ or $E_{p(b a c k w a r d)}, E_{p-p}$ and $\left|I_{b} / I_{f}\right|$ as a function of band width were considered as the diagnostic parameters via which the measurement of band width and length may be made. Since the transfer coefficient $\alpha_{a}$ and diffusion 
coefficient $D$ can be relatively easily measured from experiments (as mentioned in section 1 ), the remaining unknown parameters are the formal potential $E_{f}$ and electron transfer rate constant $k^{0}$. The next step in this work is to reduce the number of parameters needed for the characterisation of the geometry of band electrodes.

Considering that the use of peak potential as a diagnostic would require knowledge of the formal potential, the peak-to-peak separation was used instead. Voltammograms on a band electrode with variable $\mathrm{k}^{0}$ were simulated, at a scan rate of $0.2 \mathrm{~V} \mathrm{~s}^{-1}$, anodic transfer coefficient $\alpha_{\mathrm{a}}$ of 0.5 and diffusion coefficient $D$ of $1 \times 10^{-9} \mathrm{~m}^{2} \mathrm{~s}^{-1}$. The corresponding plots of the two different diagnostic parameters, $E_{p-p}$ and $\left|I_{b} / I_{f}\right|$, as a function of band width are shown in Figure 3. According to Figure 3, with a known peak to peak separation $\left(E_{p-p}\right)$ or ratio of the magnitude of backward peak current to forward peak current $\left(\left|\mathrm{I}_{\mathrm{b}} / \mathrm{I}_{\mathrm{f}}\right|\right)$, an accurate measurement of $k^{0}$ is needed to avoid a large error in the estimation of width. Consequently, the combination of plots of both $E_{p-p}$ and $\left|I_{b} / I_{f}\right|$ with variable band widths was chosen as the basis for the sought discrimination. For any given band electrode, the band width estimated from the plot of $E_{p-p}$ versus band width must be consistent with that from the plot of $\left|I_{b} / I_{f}\right|$ versus band width. In this way, by combining measurements of $E_{p-p}$ and $\left|I_{b} / I_{f}\right|$, the band width can be estimated without the knowledge of formal potential $E_{f}$ and electron transfer rate constant $k^{0}$. This facilitates the measurement of the band width without any prior knowledge of $k^{0}$. The parameters required for the measurement of band width using different analysing indicators are tabulated in Table 2.
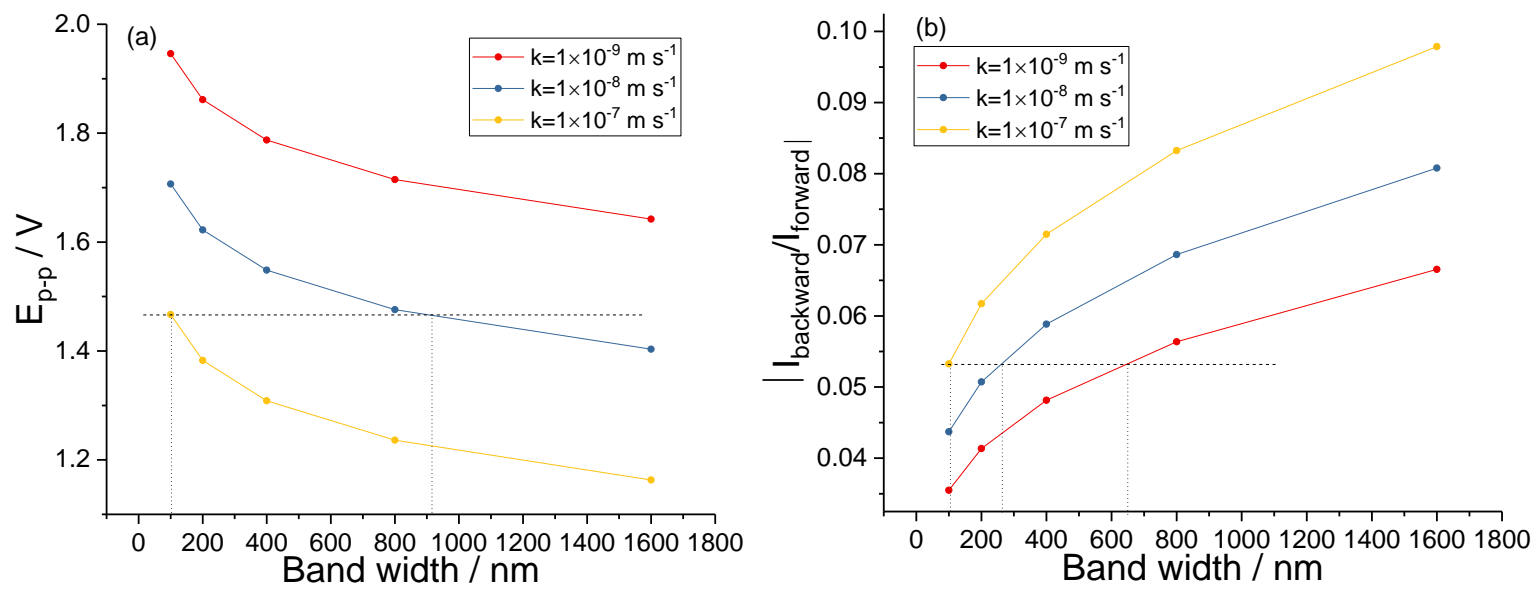

Figure 3 (a) Plot of $E_{p-p}$ as a function of band widths with variable $k^{0}$. (b) Plot of $\left|I_{\text {backward }} / I_{\text {forward }}\right|$ as a function of band widths with variable $\mathrm{k}^{0}$. Parameters in the simulations: $\alpha_{a}=\alpha_{c}=0.5, D_{(A)}=D_{(B)}=1 \times 10^{-9} \mathrm{~m}^{2} \mathrm{~s}^{-1}$. The dotted line shows the corresponding band width at different $\mathrm{k}^{0}$.

Table 2 Parameters required for the measurement of band width and length using different indicators.

\begin{tabular}{|l|l|l|l|l|}
\hline Indications & $\mathbf{E}_{\mathbf{p}(\text { forward) }} \mathbf{V S} \mathbf{E}_{\mathbf{f}}$ & $\mathbf{E}_{\mathbf{p}-\mathbf{p}}$ & $\left|\mathbf{I}_{\text {backward }} / \mathbf{I}_{\text {forward }}\right|$ & $\mathbf{E}_{\mathbf{p}-\mathbf{p}}$ and $\left|\mathbf{I}_{\text {backward }} / \mathbf{I}_{\text {forward }}\right|$ \\
\hline \multirow{4}{*}{$\begin{array}{l}\text { Parameters } \\
\text { required }\end{array}$} & $\alpha_{\mathrm{a}}$ & $\alpha_{\mathrm{a}}$ & $\alpha_{\mathrm{a}}$ & $\alpha_{\mathrm{a}}$ \\
\cline { 2 - 6 } & $\mathrm{D}$ & $\mathrm{D}$ & $\mathrm{D}$ & $\mathrm{D}$ \\
\cline { 2 - 6 } & $\mathrm{k}^{0}$ & $\mathrm{k}^{0}$ & $\mathrm{k}^{0}$ & \\
\cline { 2 - 5 } & $\mathrm{E}_{\mathrm{f}}$ & & & \\
\hline
\end{tabular}

3.2 Fully irreversible redox couple with unequal diffusion coefficients 
Considering that the electroactive redox species might have different diffusion coefficients for the oxidised and reduced species, reaction (1) was also simulated on a band electrode for case where species $A$ and $B$ have unequal diffusion coefficients but again only, with the reactant (A) present in bulk solution. Also, again the results assume that the anodic and cathodic transfer coefficients equal 0.5. Results for other transfer coefficients are given in the SI Section 3, with similar conclusions drawn as to those below.

The simulated and normalised voltammograms at the given electron transfer rate constant $k^{0}$ of $1 \times 10^{-7} \mathrm{~m} \mathrm{~s}^{-1}$ on a band electrode with variable band widths are shown in Fig 2(b), with a scan rate of $0.2 \mathrm{~V} \mathrm{~s}^{-1}$, anodic transfer coefficient $\alpha_{a}$ of 0.5 , diffusion coefficient $D_{(A)}$ of $1 \times 10^{-9} \mathrm{~m}^{2} \mathrm{~s}^{-1}$ and diffusion coefficient $D_{(B)}$ of $5 \times 10^{-10} \mathrm{~m}^{2} \mathrm{~s}^{-1}$. The comparison of waveshape was achieved through the normalisation of the voltammogram relative to the peak current (Figure 2(b)).

Similar to case where the components of the redox couple have equal diffusion coefficients, the waveshape are distinguishable with variable band widths in the case where the redox species have unequal diffusion coefficients. The results suggest that for a given unknown band electrode, it is possible to measure the width and length of a band electrode using the combination of $E_{p-p}$ and $\left|I_{\text {backward }} / I_{\text {forward }}\right|$ with the following steps:

1. Determination of $D_{A}, D_{B}, \alpha_{a}$ and $\alpha_{c}$ : Experimentally measure the diffusion coefficient $\left(D_{A}\right.$ and $\left.D_{B}\right)$ of the redox species from the steady-state current obtained on a microdisc electrode. Calculate the transfer coefficient $\left(\alpha_{\mathrm{a}}\right)$ using Tafel analysis from the experimental voltammogram for a one-electron transfer oxidative process [23]. The cathodic transfer coefficient $\alpha_{c}$ equals $\left(1-\alpha_{\mathrm{a}}\right)$.

2. Determination of $k^{0}$ and $w$ : Calculate the values of $E_{p-p}$ and $\left|I_{\text {backward }} / I_{\text {forward }}\right|$ from the experimental voltammogram. Using the simulations with a set of $k^{0}$ and band widths and the corresponding plots of $E_{p-p}$ versus band width and $\left|I_{\text {backward }} / I_{\text {forward }}\right|$ versus band. By comparing the experimental and theoretical values of $E_{p-p}$ and $\left|I_{\text {backward }} / I_{\text {forward }}\right|, k^{0}$ and band width can be estimated (the values of $k^{0}$ and $w$ are unique for a given experimental voltammogram on $a$ band electrode).

3. Determination of band length: By modelling a simulation with the measured transfer coefficient and diffusion coefficients along with the estimated $k^{0}$ and $w$, the length of the band can be calculated using Eq. 11.

$$
\text { length }=\frac{\text { Experimental } I_{\text {peak }}(\mu \mathrm{A})}{\text { Simulated } \frac{I_{\text {peak }}}{\text { length }}\left(\mu \mathrm{A} \mathrm{m^{-1 } )}\right.}
$$

\subsection{Blind test}

In order to prove the applicability of this method, blind tests with systems of unknown transfer coefficient, electron transfer rate constant, width and length of the band electrodes were made on simulated voltammograms. An example is shown in this section for a fully irreversible redox couple with unequal diffusion coefficients $\left(D_{(A)}=2 D_{(B)}=1 \times 10^{-9} \mathrm{~m}^{2} \mathrm{~s}^{-1}\right)$ following the procedures mentioned above. The voltammogram used for the blind test is shown in Figure 4. This was simulated using the data in the figure caption in Figure 4.

First, the measured diffusion coefficients of reactant $A$ and product $B$ are inferred to be $1 \times 10^{-9} \mathrm{~m}^{2} \mathrm{~s}^{-1}$ and $5 \times 10^{-10} \mathrm{~m}^{2} \mathrm{~s}^{-1}$, respectively. The anodic transfer coefficient $\alpha_{a}$ is 0.5 . These data, in experimental 
reality, would be found from steady-state microdisc voltammetry on scope of pure A and of pure B, and use Tafel analysis of experimental voltammograms.

Second, from the voltammogram, the measured $E_{p-p}$ is $1.2080 \mathrm{~V}$ and the $\left|\mathrm{I}_{\text {backward }} / I_{\text {forward }}\right|$ is 0.09393 . Voltammograms with a set of $\mathrm{k}^{0}$ with variable band widths were simulated. With the known diffusion coefficients and transfer coefficient, the theoretical plots were obtained as shown in Figure 5. The experimental data is the dashed line. The corresponding band widths at each $\mathrm{k}^{0}$ are shown as dotted line. From the plots, it shows that the corresponding band widths are relatively consistent in both plots with an electron transfer rate constant $\mathrm{k}^{0}$ of $7.5 \times 10^{-8} \mathrm{~m} \mathrm{~s}^{-1}$. The band width was therefore estimated as $1056 \mathrm{~nm}$.

Third, further simulation was done with the known transfer coefficient of 0.5 , diffusion coefficients of reactant and product of $1 \times 10^{-9} \mathrm{~m}^{2} \mathrm{~s}^{-1}$ and $5 \times 10^{-10} \mathrm{~m}^{2} \mathrm{~s}^{-1}$, estimated rate constant of $7.5 \times 10^{-8} \mathrm{~m} \mathrm{~s}^{-1}$ and band width of $1056 \mathrm{~nm}$. The corresponding voltammogram was normalised to its length as shown in Figure 6. The length of the band in the blind test was then calculated using Eq.11 and was $0.01801 \mathrm{~m}$. Therefore, the band width was estimated as $1056 \mathrm{~nm}$ with a length of $0.01801 \mathrm{~m}$ (the true width is $1058 \mathrm{~nm}$ and the true length is $0.018 \mathrm{~m}$ ). The errors are $0.19 \%$ and $0.034 \%$ in width and length, respectively as shown in Table 3 'Test 1 '.

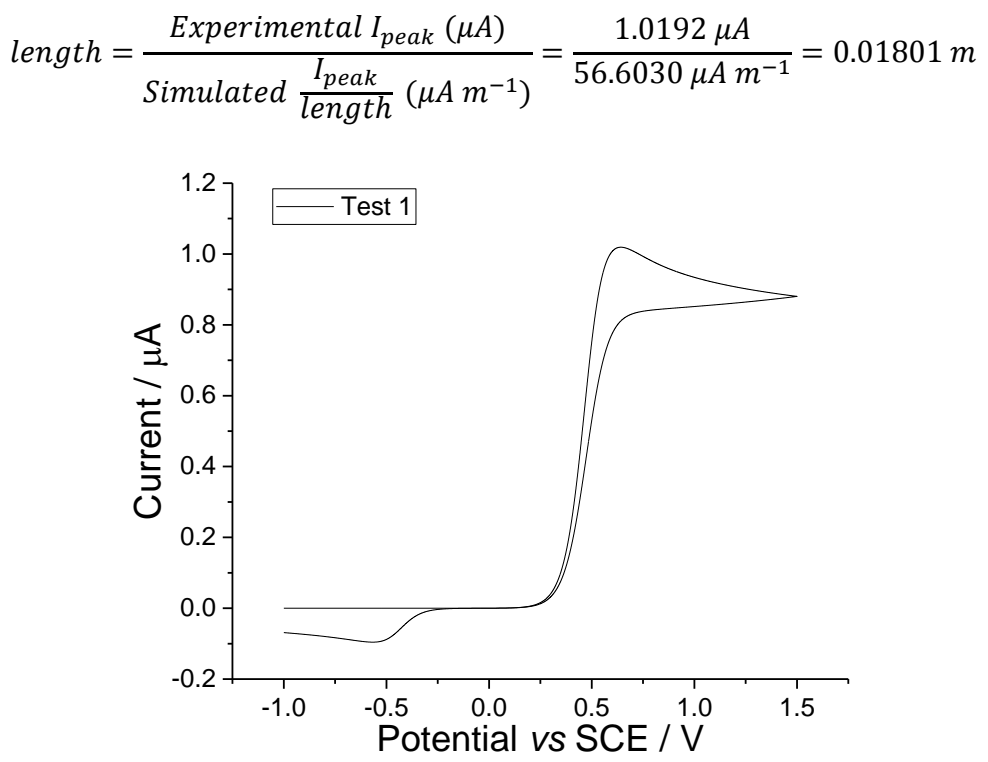

Figure 4 Blind test on a band electrode with unknown band length and width. Known parameters in the simulation: $c=1$ $\mathrm{mM}, v=0.2 \mathrm{~V} \mathrm{~s}^{-1}, \alpha_{\mathrm{a}}=\alpha_{\mathrm{c}}=0.5, \mathrm{D}_{(\mathrm{A})}=1 \times 10^{-9} \mathrm{~m}^{2} \mathrm{~s}^{-1}, \mathrm{D}_{(\mathrm{B})}=5 \times 10^{-10} \mathrm{~m}^{2} \mathrm{~s}^{-1}$. 

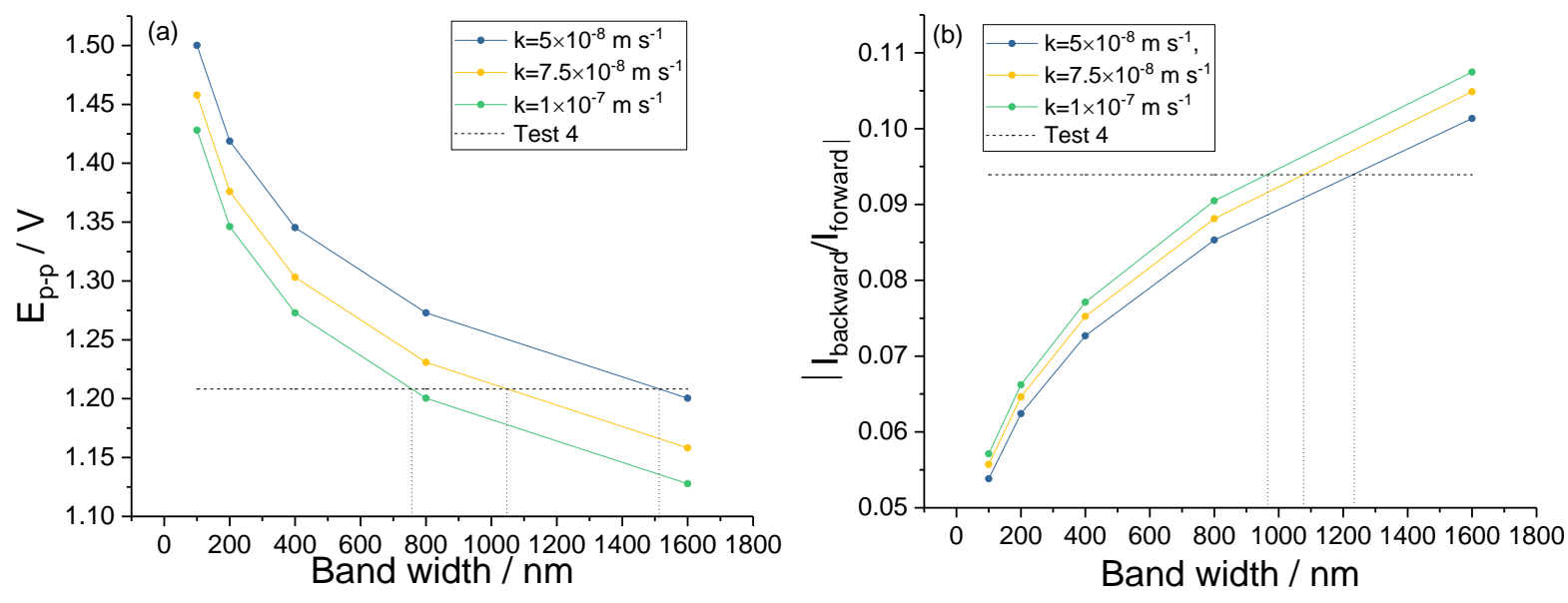

Figure 5 (a) Plot of $E_{p-p}$ as a function of band widths with variable $k^{0}$. (b) Plot of $\left|I_{\text {backward }} / I_{\text {forward }}\right|$ as a function of band widths with variable $\mathrm{k}^{0}$. Parameters in the simulations: $\alpha_{\mathrm{a}}=\alpha_{\mathrm{c}}=0.5, \mathrm{D}_{(\mathrm{A})}=1 \times 10^{-9} \mathrm{~m}^{2} \mathrm{~s}^{-1}, \mathrm{D}_{(\mathrm{B})}=5 \times 10^{-10} \mathrm{~m}^{2} \mathrm{~s}^{-1}$. The dashed line is the measured value of $E_{p-p}$ and $\left|I_{\text {backward }} / I_{\text {forward }}\right|$ from Fig 4 . The dotted line shows the corresponding band width at different $\mathbf{k}^{0}$.

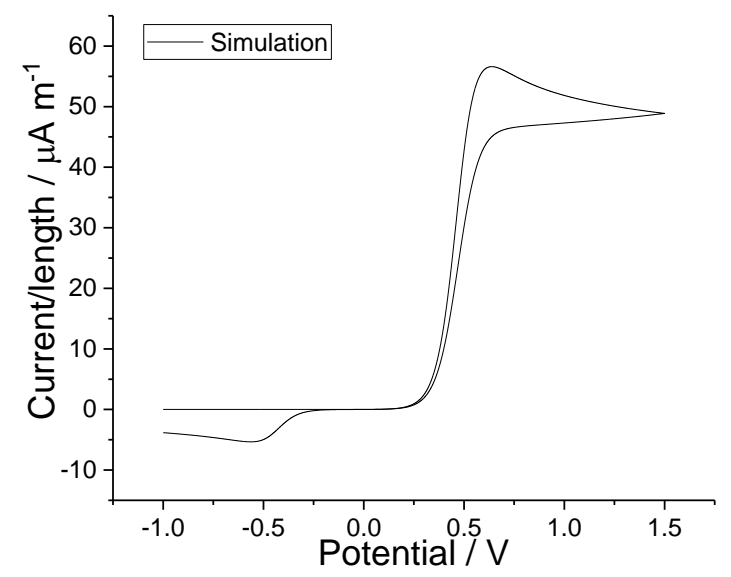

Figure 6 Normalised voltammogram on a band electrode with known transfer coefficient and diffusion coefficients, estimated rate constant and band width. Parameters in the simulation: $\alpha_{a}=0.5, \alpha_{c}=0.5, D_{(A)}=1 \times 10^{-9} \mathrm{~m}^{2} \mathrm{~s}^{-1}, D_{(B)}=5 \times$ $10^{-10} \mathrm{~m}^{2} \mathrm{~s}^{-1} \cdot \mathrm{v}=0.2 \mathrm{~V} \mathrm{~s}^{-1}, \mathrm{E}_{\mathrm{f}}=0 \mathrm{~V}, \mathrm{I}=1 \times 10^{-2} \mathrm{~m}, \mathrm{k}^{0}=7.5 \times 10^{-8} \mathrm{~m} \mathrm{~s}^{-1}$, band width $=1056 \mathrm{~nm}$.

Table 3 Estimated and true band widths and lengths for blind tests 1-4. $v=0.2 \mathrm{~V} \mathrm{~s} s^{-1}, \alpha_{a}=\alpha_{c}=0.5$. In Test $1^{\mathrm{a}}: \mathrm{D}_{(\mathrm{A})}=1 \times 10^{-9}$ $\mathrm{m}^{2} \mathrm{~s}^{-1}, \mathrm{D}_{(\mathrm{B})}=5 \times 10^{-10} \mathrm{~m}^{2} \mathrm{~s}^{-1} \cdot$ In Test $2-4^{\mathrm{b}}, \mathrm{D}_{(\mathrm{A})}=1 \times 10^{-10} \mathrm{~m}^{2} \mathrm{~s}^{-1}, \mathrm{D}_{(\mathrm{B})}=0.5 \times 10^{-10} \mathrm{~m}^{2} \mathrm{~s}^{-1}$.

\begin{tabular}{|c|c|c|c|c|}
\hline & & Estimated & True & Error \\
\hline \multirow{2}{*}{$\begin{array}{l}\text { Test } 1^{\mathrm{a}} \\
\left(\alpha_{\mathrm{a}}=0.5, \alpha_{\mathrm{c}}=0.5\right)\end{array}$} & Width (w) / nm & 1056 & 1058 & $0.19 \%$ \\
\hline & Length (I) / m & 0.015801 & 0.018 & $0.034 \%$ \\
\hline \multirow{2}{*}{$\begin{array}{l}\text { Test } 2^{b} \\
\left(\alpha_{a}=0.3, \alpha_{c}=0.7\right)\end{array}$} & Width $(\mathrm{w}) / \mathrm{nm}$ & 1176 & 1148 & $2.4 \%$ \\
\hline & Length (I) / m & 0.0328 & 0.033 & $0.6 \%$ \\
\hline \multirow{2}{*}{$\begin{array}{l}\text { Test } 3^{b} \\
\left(\alpha_{a}=0.4, \alpha_{c}=0.6\right)\end{array}$} & Width (w) / nm & 1424 & 1350 & $5.5 \%$ \\
\hline & Length (I) / m & 0.0444 & 0.045 & $1.3 \%$ \\
\hline \multirow{2}{*}{$\begin{array}{l}\text { Test } 4^{b} \\
\left(\alpha_{a}=0.5, \alpha_{c}=0.5\right)\end{array}$} & Width (w) / nm & 312 & 306 & $3.7 \%$ \\
\hline & Length (I) / m & 0.0157 & 0.0156 & $0.64 \%$ \\
\hline
\end{tabular}

In order to prove the applicability to the cases where the redox species have lower diffusion coefficients $\left(D_{(A)}=2 D_{(B)}=1 \times 10^{-10} \mathrm{~m}^{2} \mathrm{~s}^{-1}\right.$ ), blind tests (test 2, 3 and 4) where the anodic transfer 
coefficient equal 0.3, 0.4 and 0.5 were tried. According to the results in Table 3 'Test $2-4$ ', it is shown that by using this method, in all cases the error in width is $3.9 \% \pm 1.6 \%$ and the error in length is $0.85 \% \pm 0.40 \%$. The analysing details are presented in the SI Section 4 .

\section{Conclusions:}

This work validates an entirely voltammetric method to characterise the dimensions of a band electrode. With a given unknown band electrode, the band width and length can be estimated electrochemically by using a fully irreversible redox couple without any prior knowledge of electron transfer rate constant $\mathrm{k}^{0}$ and/or the formal potential $\mathrm{E}_{\mathrm{f}}$. Considering that the diffusion coefficient of the electroactive species and the transfer coefficient can be measured from experiments, the peakto-peak separation $E_{p-p}$ and the ratio of the magnitude of backward peak current to forward peak current $\left|\mathrm{I}_{\text {backward }} / \mathrm{I}_{\text {forward }}\right|$ are combined together as the indicators to estimate the electron transfer rate constant and the band width. From the blind test, the estimated band width and length gave errors of $\sim 4 \%$ and $\sim 1 \%$, respectively.

\section{Acknowledgement}

D. Li thanks for the China Scholarship Council and the University of Oxford for supporting her DPhil research.

\section{References:}

1. J. Durst, C. Simon, F. Hasche, and H. A. Gasteiger, J. Electrochem. Soc. 162, F190 (2014).

2. W. Sheng, H. A. Gasteiger, and Y. Shao-Horn, J. Electrochem. Soc. 157, B1529 (2010).

3. E. J. F. Dickinson and R. G. Compton, J. Electroanal. Chem. 655, 23 (2011).

4. C. Amatore, Anal. Chem. 68, 4377 (1996).

5. K. Stulík, C. Amatore, K. Holub, V. Marecek, and W. Kutner, Pure Appl. Chem. 72, 1483 (2000).

6. C. A. Amatore, M. R. Deakin, and M. Wightman, J. Electroanal. Chem. 206, 23 (1986).

7. D. Pletcher, in Microelectrodes Theory Appl., edited by M. I. Montenegro, M. A. Queirós, and J. L. Daschbach (Springer Netherlands, Dordrecht, 1991), pp. 463-475.

8. A. M. Bond, Analyst 119, 1 (1994).

9. J. Heinze, Angew. Chemie Int. Ed. English 32, 1268 (1993).

10. R. J. Forster, Chem. Soc. Rev. 23, 289 (1994).

11. R. G. Compton and C. E. Banks, Understanding Voltammetry, 3rd Edn (WORLD SCIENTIFIC, Singapore, 2018).

12. K. R. Wehmeyer, M. R. Deakin, and R. M. Wightman, Anal. Chem. 57, 1913 (1985).

13. I. A. Sliver, Phil. Trans. R. Soc. Lond. B316, 161 (1987).

14. E. Llaudet, S. Hatz, M. Droniou, and N. Dale, Anal. Chem. 77, 3267 (2005). 
15. K. Ngamchuea, C. Lin, C. Batchelor-Mcauley, and R. G. Compton, Anal. Chem. 89, 3780 (2017).

16. B. J. Seddon, M. J. Eddowes, A. Firth, A. E. Owen, and H. H. J. Girault, Electrochim. Acta 36, 763 (1991).

17. P. U. Prayikaputri, J. Gunlazuardi, and T. A. Ivandini, IOP Conf. Ser. Mater. Sci. Eng. 188, 12035 (2017).

18. P. J. Welford, J. Freeman, S. J. Wilkins, J. D. Wadhawan, C. E. W. Hahn, and R. G. Compton, Anal. Chem. 73, 6088 (2001).

19. J. D. Wadhawan, P. J. Welford, K. Yunus, A. C. Fisher, and R. G. Compton, J. Braz. Chem. Soc. 14, 510 (2003).

20. R. Lin, T. M. Lim, and T. Tran, Electrochem. Commun. 86, 135 (2018).

21. Y. Wang, J. G. Limon-Petersen, and R. G. Compton, J. Electroanal. Chem. 652, 13 (2011).

22. M. P. Nagale and I. Fritsch, Anal. Chem. 70, 2908 (1998).

23. D. Li, C. Lin, C. Batchelor-McAuley, L. Chen, and R. G. Compton, J. Electroanal. Chem. 826, 117 (2018).

24. R. Guidelli, R. G. Compton, J. M. Feliu, E. Gileadi, J. Lipkowski, W. Schmickler, and S. Trasatti, Pure Appl. Chem. 86, 259 (2014).

25. R. Guidelli, R. G. Compton, J. M. Feliu, E. Gileadi, J. Lipkowski, W. Schmickler, and S. Trasatti, Pure Appl. Chem. 86, 245 (2014).

26. R. G. Compton, E. Laborda, and K. R. Ward, Understanding Voltammetry: Simulation of Electrode Processes (Imperial College Press, London, 2013).

27. J. D. Seibold, E. R. Scott, and H. S. White, J. Electroanal. Chem. 264, 281 (1989). 